\title{
The Impact of Rate of Feeding Advancement after Early Initiation of Enteral Nutrition in Critically Ill, Underweight Patients: A Single-Center Retrospective Chart Review
}

\author{
Satomi Ichimaru1, Maren Sono², Hidetoshi Fujiwara3, Ryutaro Seo², Koichi Ariyoshi² \\ ${ }^{1}$ Department of Nutrition Management, Osaka Saiseikai Nakatsu Hospital, Osaka, Japan \\ ${ }^{2}$ Department of Emergency Medicine, Kobe City Medical Center General Hospital, Kobe, Japan \\ ${ }^{3}$ Department of Pharmacy, Kobe City Medical Center General Hospital, Kobe, Japan \\ Email: satomi.ichimaru@gmail.com
}

How to cite this paper: Ichimaru, S., Sono, M., Fujiwara, H., Seo, R. and Ariyoshi, K. (2016) The Impact of Rate of Feeding Advancement after Early Initiation of Enteral Nutrition in Critically Ill, Underweight Patients: A Single-Center Retrospective Chart Review. Food and Nutrition Sciences, 7, 939-954.

http://dx.doi.org/10.4236/fns.2016.711093

Received: April 20, 2016

Accepted: September 9, 2016

Published: September 12, 2016

Copyright $\odot 2016$ by authors and Scientific Research Publishing Inc. This work is licensed under the Creative Commons Attribution International License (CC BY 4.0).

http://creativecommons.org/licenses/by/4.0/ c) (i) Open Access

\begin{abstract}
Background: The optimal rate of feeding advancement after initiation of early enteral nutrition (EEN) for underweight, critically ill patients is unknown. Methods: We conducted a retrospective chart review in intensive care unit (ICU) patients with a body mass index (BMI) $<20.0 \mathrm{~kg} / \mathrm{m}^{2}$. Patients were categorized into Group R, which reached the energy target within 3 days of EEN initiation, and Group S, which reached the energy target 4 or more days after EEN initiation. Results: A total of 65 patients with a median age of 73 years were included in the study. No significant differences were observed between the two groups for all-cause mortality, ICU-free days, or length of hospital stay. Ventilator-free days (VFDs) were significantly fewer in Group R than in Group S (18.0 [0.0 - 22.0] vs. 21.0 [16.3 - 24.8] days; P = 0.046). A significantly higher number of patients requiring mechanical ventilation (MV) at hospital discharge were observed in Group R than in Group S $(29 \%$ vs. $8 \%$; P = 0.030). Multivariable analyses with adjustment for confounders found that days required to reach target energy intake after EEN initiation were significantly and independently associated with the requirement for MV at hospital discharge, but not with VFDs. Conclusion: A slow rate of feeding advancement after initiation of EEN in critically ill patients having a BMI of $<20.0 \mathrm{~kg} / \mathrm{m}^{2}$ might be associated with a reduced requirement for MV at hospital discharge. These results require confirmation in a large multicenter trial of underweight, critically ill patients.
\end{abstract}




\section{Keywords}

Critical Illness, Underweight, Mechanical Ventilation, Early Enteral Nutrition, Rate of Feeding Advancement

\section{Introduction}

Nutritional support is essential for the management of intensive care unit (ICU) patients. Enteral nutrition (EN) is the preferred route for nutritional support in critically ill patients [1]. Current clinical guidelines recommend that EN be initiated within 24 to $48 \mathrm{~h}$ of admission [1]-[3]. This concept of early EN (EEN) has become widely accepted due to reduction in the rate of infectious complications and mortality [1]-[3].

Following the initiation of EEN, clinical guidelines recommend that feeding be advanced toward a goal rate over the next $48-72 \mathrm{~h}$ [1]. However, several studies recommend the slow advancement of energy intake, noting improved outcomes in critically ill patients with initial enteral underfeeding [4]-[8]. Importantly, however, many of these studies were conducted in Western countries in patients with normal weight or excessive body weight (BW). For underweight patients with limited nutritional reserves, advancing feeding too slowly might result in undernutrition or poor clinical outcomes [9]-[14]. We previously reported that reduced energy intake during the first week of ICU admission was associated with a reduced duration of mechanical ventilation (MV) in critically ill, underweight patients [15]. However, that study included patients who did not receive EEN or in whom oral intake or parenteral nutrition (PN) was initiated within the first week of admission. Therefore, the association observed in our previous report might be influenced by patients who could progress to oral intake early, or who were intentionally underfed thorough PN [16]. To our knowledge, the optimal rate of enteral feeding advancement after initiation of EEN in underweight and critically ill remains unclear.

Here, to examine the impact of feeding advancement rate after the initiation of EEN on the mortality and morbidity of underweight and critically ill patients, we performed a retrospective chart review of patients with a body mass index $(\mathrm{BMI})<20.0 \mathrm{~kg} / \mathrm{m}^{2}$.

\section{Materials and Methods}

\subsection{Study Population}

This single-center retrospective chart review was conducted in an 8-bed emergency intensive care unit (EICU) of a tertiary teaching hospital. The EICU is an emergency admission ward in which patients with serious emergency medical or surgical conditions receive intensive care. Critically ill patients transferred from general wards or following elective surgery are admitted to other ICUs. The study received approval from the ethics committee of the study institution. Owing to the nature of the study, the requirement for informed patient consent was waived.

Consecutive patients admitted to the EICU from August 2011 to July 2014 were 
screened for eligibility. If the patients in our previous study met the inclusion criteria below, they were also included in the present study, as the two study periods overlapped (Aug 2011-Dec 2012) [15]. Critically ill adult patients with a BMI of $<20.0 \mathrm{~kg} / \mathrm{m}^{2}$ who were mechanically ventilated and initiated EN within the first $48 \mathrm{~h}$ of admission and who remained in the EICU for $72 \mathrm{~h}$ or more were include in the study. The decision of when to initiate and advance EN was made following discussion among the attending and EICU physicians based on their preference and/or the patient's hemodynamic stability, clinical condition, and underlying diseases. Exclusion criteria were as follows: aged $<18$ years, pregnant or lactating, readmission to the EICU within the same hospitalization period, under mask ventilation, withdrawal from treatment in the first week, BMI $\geq 20.0 \mathrm{~kg} / \mathrm{m}^{2}$, missing BMI data, or initiation of oral or parenteral nutrition within the first week of admission to the EICU.

\subsection{Data Collection}

Data were obtained from the medical records of patients. The following baseline demographic characteristics were recorded: age, sex, body weight and height on admission, and BMI. BMI was calculated based on weight $(\mathrm{kg}) /$ height $\left(\mathrm{m}^{2}\right)$ on admission. The following baseline clinical characteristics were recorded: Acute Physiology and Chronic Health Evaluation (APACHE) II Score (which ranges from 0 to 71, with higher scores indicating more severe illness) [17] and Sequential Organ Failure Assessment (SOFA) Score (which ranges from 0 to 24 , with higher scores indicating more severe organ compromise) [18] in the first $24 \mathrm{~h}$ of admission; surgical or medical admission; admission from emergency department, emergency ward, operating room, or other hospital; primary diagnosis in EICU for cardiovascular, vascular, respiratory, gastrointestinal, neurological disorders, trauma, sepsis, burn, metabolic disorder, or renal disorder; Charlson Comorbidity Index [19]; and comorbidities including diabetes mellitus, dialysis-dependent renal failure, cardiac disease, anemia (hemoglobin level $<8.0 \mathrm{~g} / \mathrm{dL}$ ) [20], and chronic obstructive pulmonary disease. The following nutritional characteristics were recorded: time to EEN initiation from EICU admission, days to reach target energy intake from EEN initiation, and mean daily energy and protein intake during the first week of EICU admission. Total energy intake included intake via parenteral and enteral routes; glucose infusion used for fluid support, drug dilution and correction of hypoglycemia; and lipids delivered together with sedatives (e.g., propofol).

An energy target of $25 \mathrm{kcal} / \mathrm{kg}$ /day was set as the required energy for the majority of critically ill patients [1] [3]. In the present study, patients were categorized into a rapid advancement group (Group R), which reached the energy target within 3 days of EEN initiation, or a slow advancement group (Group $S$ ), which reached the energy target 4 or more days after EEN initiation. A cut-off value of 3 days was used as clinical guidelines recommend that feeding be advanced toward a goal rate over the next $48-72 \mathrm{~h}$ following the initiation of EEN [1].

\subsection{Clinical Outcomes}

Clinical outcomes in Groups R and S were compared. The following variables were 
analyzed:

1) All-cause mortality in the hospital and EICU.

2) ICU-free days and length of hospital stay. ICU-free days were defined as the number of days between successful transfer to a general ward and Day 28 after EICU admission. ICU-free days were 0 if the patient died before Day 28 or stayed in the EICU or other ICUs for $\geq 28$ days. For the length of hospital stay, patients who died during hospitalization were excluded from the analysis.

3) Ventilator-free days (VFDs). VFDs were defined as the number of days between successful weaning from MV and Day 28 after EICU admission. VFDs were 0 if the patient died before Day 28 or required MV for $\geq 28$ days.

4) Number of patients requiring continuous or intermittent MV via tracheostomy at hospital discharge. The decision of when to wean from MV was made following discussion among the attending and/or EICU physicians.

5) Number of patients undergoing tracheostomy in the EICU or hospital. The decision of when to perform a tracheostomy was made following discussion among the attending and/or EICU physicians.

6) Antibiotic-free days as the number of days during the 28 days after living patients had been admitted to the EICU and had not received any antibiotics as treatment for infections or as prophylaxis.

7) Inflammatory index, as maximum plasma C-reactive protein (CRP) level during the first 28 days after EICU admission.

8) Number of patients clinically diagnosed with pneumonia by EICU physicians during the first 28 days after EICU admission, and number of patients who developed ventilator-associated pneumonia (VAP) [21].

9) Number of patients exhibiting liver dysfunction, defined as a total bilirubin level of $>1.2 \mathrm{mg} / \mathrm{dL}$ during the first 28 days after EICU admission.

10) Number of patients exhibiting renal dysfunction, as determined by an increase in serum creatinine level of $>1.2 \mathrm{mg} / \mathrm{dL}$ or need for renal replacement therapy during the first 28 days after EICU admission.

11) Number of patients exhibiting hypoglycemia, defined as a blood glucose level of $<70 \mathrm{mg} / \mathrm{dL}$ [22], during the first week in the EICU and for 28 days after EICU admission.

12) Number of patients receiving insulin therapy and average daily insulin dose in the first week and 28 days after EICU admission. Target glucose level was set as 100 to $180 \mathrm{mg} / \mathrm{dL}$.

13) Number of patients exhibiting hypophosphatemia, defined as a serum phosphorus $(\mathrm{P})$ concentration $<2.7 \mathrm{mg} / \mathrm{d}$ [23], during the first week and 28 days after EICU admission. However, serum $P$ concentration was not examined in all patients, because the frequency of laboratory testing was not standardized between physicians. Further, lowest serum $\mathrm{P}$ concentrations and the dose of $\mathrm{P}$ via parenteral or enteral administration to correct for depletion were compared between groups. P content of enteral formulas given as maintenance dosing was excluded from this analysis. $\mathrm{P}$ dose was calcu- 
lated with consideration to not only serum P level, but also to the degree of total body depletion and renal function.

\subsection{Statistical Analysis}

Data for continuous variables are presented as median and inter quartile range and for categorical variables as numbers and percentages. Groups were compared using the Mann-Whitney U test (continuous data) and Fisher's exact test (categorical data). We used the nonparametric test for continuous variables as the relatively small sample size underestimated the distribution assumptions for parametric tests. Multiple regression and multiple logistic regression analyses were conducted with VFDs and the requirement for MV at hospital discharge as the dependent variables; and days to reach target energy intake from EEN initiation, initial SOFA score, admission source, category of admission, and time to EEN initiation from EICU admission as independent variables. Multivariable analyses were conducted to identify the impact of days to reach target energy intake from EEN initiation on outcomes following control for differences in patients' baseline characteristic. Statistical analyses were conducted using SPSS statistical software v. 21 (IBM, Armonk, NY, USA). P values $<0.05$ were considered significant.

\section{Results}

Among the 1993 patients who were assessed for eligibility, 65 met the criteria and were included in the study (Figure 1). Of these patients, the initial $29(45 \%)$ were also included in our previous study [15]. Reasons for exclusion were as follows: aged $<18$ years ( $\mathrm{n}=$ 12), EICU length of stay $<72 \mathrm{~h}(\mathrm{n}=1265)$, no mechanical ventilation within $48 \mathrm{~h}$ of admission $(\mathrm{n}=218)$, re-admittance to the EICU during the same hospitalization period $(\mathrm{n}=20)$, pregnant or lactating $(\mathrm{n}=3)$, withdrawal from treatment during the first week ( $n=68)$, oral intake within the first week $(n=80), B M I \geq 20.0 \mathrm{~kg} / \mathrm{m}^{2}(\mathrm{n}=212)$, lack of BMI data $(n=21)$, no initiation of EN within $48 \mathrm{~h}$ of admission $(\mathrm{n}=28)$, or initiation of PN within the first week of EICU admission $(n=1)$.

\subsection{Patient Characteristics}

Table 1 shows the baseline demographic, clinical, and nutritional characteristics of Group R and Group S. Demographics did not significantly differ between the two groups. Median patient age was 72.8 years and median BMI was $17.8 \mathrm{~kg} / \mathrm{m}^{2}$. APACHE II score did not significantly differ between groups. Initial SOFA score was higher in Group R than in Group S (10 [9 - 13] vs. 9 [8 - 10]; P = 0.029). The number of surgical patients and patients who admitted to EICU from operating room were higher in Group S than in Group R. Of the patients, half $(\mathrm{n}=33)$ were diagnosed with a neurological disorder, of whom 23 had intracranial hemorrhage, 4 had seizure, and 2 had spinal cord injury. Only Group R had 6 sepsis patients, and only Group S had 3 trauma patients. No patients were diagnosed with a gastrointestinal disorder. Charlson Comorbidity Index did not significantly differ between groups.

Initiation of EN for patients in Group R was earlier than in Group S (14.5 [4.7 - 21.9] 


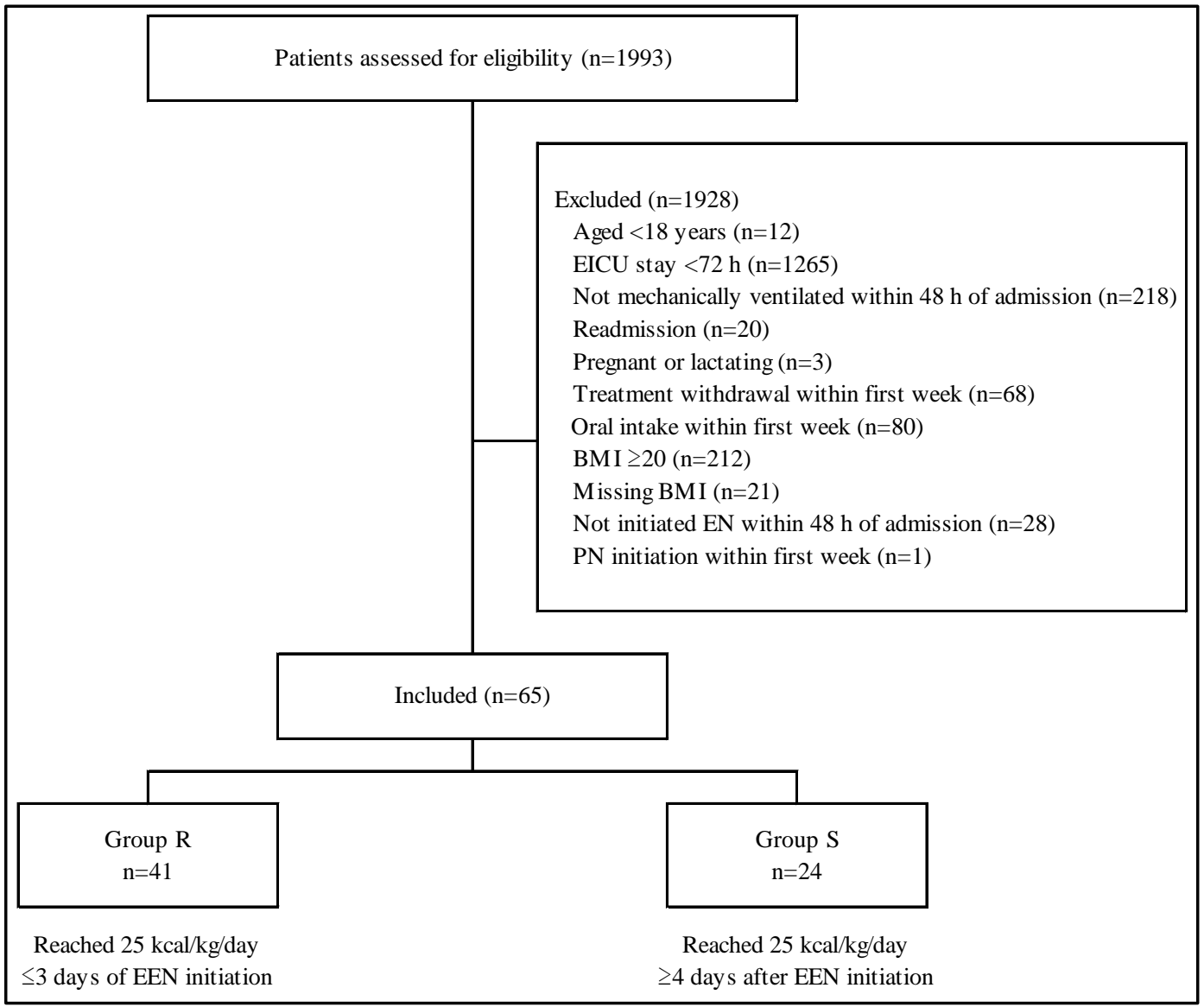

Figure 1. Flow chart of included patients. EEN = early enteral nutrition, EICU = emergency intensive care unit, $\mathrm{PN}=$ parenteral nutrition.

vs. 24.7 [12.6 - 36.4] h; $\mathrm{P}=0.010$ ). Median time to reach target energy intake from EEN initiation was 2 days in Group R and 5 days in Group S. Energy and protein intakes in the first week of EICU admission were higher in Group R than in Group S (24.6 [22.1 28.1] vs. 17.7 [13.6 - 20.4] kcal/kg BW/day; P < 0.001, 1.1 [0.9 - 1.3] vs. 0.7 [0.5 - 0.9] g; $\mathrm{P}<0.001$, respectively).

\subsection{Outcomes}

Table 2 shows patient outcomes. There were no significant differences in all-cause mortality in the EICU or hospital between the two groups. ICU-free days and length of hospital stay were not also significantly different. VFDs were significantly lower in Group R (18.0 [0.0 - 22.0] vs. 21.0 [16.3 - 24.8] days; P = 0.046). Significantly more patients required MV at hospital discharge in Group R than in Group S (29\% vs. 8\%; P = 0.030 ). In contrast, the number of patients undergoing tracheostomy during their stay in the EICU or hospital did not significantly differ between the two groups. Further, no significant differences were noted between the two groups regarding in antibiotic-free days, serum CRP level, development of pneumonia, incidence of liver or renal dysfunction, or glycemic control, or in the development of hypophosphatemia, lowest serum $\mathrm{P}$ 
Table 1. Demographics, clinical characteristics, and nutritional characteristics of group R and group $S$.

\begin{tabular}{|c|c|c|c|}
\hline \multirow{3}{*}{ Characteristic } & Group R & Group S & \multirow[b]{2}{*}{$P$ value } \\
\hline & $\begin{array}{c}\text { Rapid EN } \\
\text { advancement }\end{array}$ & $\begin{array}{c}\text { Slow EN } \\
\text { advancement }\end{array}$ & \\
\hline & $\mathrm{N}=41$ & $\mathrm{~N}=24$ & \\
\hline \multicolumn{4}{|l|}{ Demographic } \\
\hline Age, years; median (IQR) & $72.8(64.1-83.0)$ & $73.6(61.9-81.0)$ & 0.563 \\
\hline Sex & & & 0.135 \\
\hline Female, n (\%) & $22(54)$ & $17(71)$ & \\
\hline Male, n (\%) & $19(46)$ & $7(29)$ & \\
\hline Height, cm; median (IQR) & $160.0(153.0-170.0)$ & $162.5(154.3-170.0)$ & 0.801 \\
\hline Weight, kg; median (IQR) & $46.5(41.5-53.4)$ & $45.0(41.9-49.5)$ & 0.719 \\
\hline BMI, kg/m²; median (IQR) & $18.2(16.4-19.2)$ & $17.7(16.1-19.1)$ & 0.634 \\
\hline \multicolumn{4}{|l|}{ Clinical characteristic } \\
\hline APACHE II score (IQR) & $21.0(18.5-31.5)$ & $22.0(19.0-27.5)$ & 0.563 \\
\hline Initial SOFA score (IQR) & $10.0(9.0-13.0)$ & $9.0(8.0-10.0)$ & 0.029 \\
\hline Admission category, n (\%) & & & 0.001 \\
\hline Medical & $28(68)$ & $6(25)$ & \\
\hline Surgical & $13(32)$ & $18(75)$ & \\
\hline Source of admission & & & 0.007 \\
\hline Emergency department & $21(51)$ & $12(50)$ & \\
\hline Emergency ward & $7(17)$ & $1(4)$ & \\
\hline Operating room & $6(15)$ & $11(46)$ & \\
\hline Other hospital & $7(17)$ & $0(0)$ & \\
\hline Primary EICU diagnosis, n (\%) & & & 0.052 \\
\hline Cardiovascular or vascular disorder & $6(15)$ & $1(4)$ & \\
\hline Respiratory disorder & $7(17)$ & $3(13)$ & \\
\hline Gastrointestinal disorder & $0(0)$ & $0(0)$ & \\
\hline Neurologic disorder & $18(44)$ & $15(63)$ & \\
\hline Sepsis & $6(15)$ & $0(0)$ & \\
\hline Trauma & $0(0)$ & $3(13)$ & \\
\hline Metabolic disorder & $2(5)$ & $2(8)$ & \\
\hline Burn & $1(2)$ & $0(0)$ & \\
\hline Renal disorder & $1(2)$ & $0(0)$ & \\
\hline \multicolumn{4}{|l|}{ Comorbidity } \\
\hline Charlson comorbidity index; median (IQR) & $5.0(3.5-6.0)$ & $5.0(3.0-5.0)$ & 0.234 \\
\hline Diabetes mellitus, n (\%) & $4(10)$ & $1(4)$ & 0.385 \\
\hline Dialysis dependent renal failure, n (\%) & $3(7)$ & $0(0)$ & 0.244 \\
\hline Chronic obstructive pulmonary disease, n (\%) & $3(7)$ & $2(8)$ & 0.615 \\
\hline Cardiac disease, $\mathrm{n}(\%)$ & $8(20)$ & $2(8)$ & 0.201 \\
\hline
\end{tabular}




\section{Continued}

Anemia (hemoglobin $<8.0 \mathrm{~g} / \mathrm{dl}$ on EICU

admission), $\mathrm{n}(\%)$

Nutritional characteristic

Time to initiation of EEN from EICU admission, h; median (IQR)

Days to reach target energy intake from EEN initiation, day; median (IQR)

Average energy intake during first week in EICU, kcal/kg/day; median (IQR)

Average protein intake during first week in EICU, g/kg/day; median (IQR)
$3(7)$

$1(4)$

0.527

$14.5(4.7-21.9)$

$24.7(12.6-36.4)$

0.010

$2.0(2.0-3.0)$

$5.0(4.0-7.0)$

$<0.001$

$24.6(22.1-28.1)$

$17.7(13.6-20.4)$

$<0.001$

$1.1(0.9-1.3)$

$0.7(0.5-0.9)$

$<0.001$

Data were provided as median and interquartile range for continuous variables and as number and percentage for categorical variables. Mann-Whitney $U$ test was used for continuous data and Fisher's exact test for categorical data. Group R reached $25 \mathrm{kcal} / \mathrm{kg} /$ day within 3 days of EEN initiation; Group S reached $25 \mathrm{kcal} / \mathrm{kg} /$ day 4 or more days after EEN initiation. Energy intake included intake via enteral and parenteral routes; glucose infusions used for fluid support, drug dilution and correction of hypoglycemia; and lipids delivered with sedatives (e.g., propofol). Either oral or parenteral nutrition was not initiated within the first week of EICU admission. APACHE II $=$ The Acute Physiology and Chronic Health Evaluation II, EEN = early enteral nutrition, EICU = emergency intensive care unit, $\mathrm{EN}=$ enteral nutrition, $\mathrm{IQR}=$ interquartile range, SOFA = Sequential Organ Failure Assessment.

concentrations, or dose of $\mathrm{P}$ required for the treatment of hypophosphatemia.

\subsection{Multivariable Analyses}

Because VFDs might have been influenced by factors other than the rate of feeding advancement that were analyzed in our study, we also conducted a multiple regression analysis with VFDs as the dependent variable, using days to reach target energy intake from EEN initiation, initial SOFA score, category of admission, admission source and time to initiation of EEN from EICU admission as independent variables. Results showed no independent correlation between the number of days to reach target energy intake from EEN initiation and VFDs (regression coefficient $=0.500 ; 95 \%$ confidence interval, -0.420 - 1.419).

In a similar manner, a multiple logistic regression analysis was also conducted to assess the independent effect of days to reach target energy intake from EEN initiation on the requirement for MV at hospital discharge after controlling for other factors, namely days to reach target energy intake from EEN initiation, initial SOFA score, category of admission, source of admission and time to initiation of EEN from EICU admission. Days to reach target energy intake from EEN initiation was significantly and independently associated with the requirement for MV at hospital discharge (Table 3).

\section{Discussion}

In this study, we found no significant differences in the all-cause mortality or number of ICU- and length of hospital stay between patients with BMI $<20.0 \mathrm{~kg} / \mathrm{m}^{2}$ who received a rapid or slow rate of feeding advancement after initiation of EEN in the EICU. However, VFDs were significantly lower and the requirement for MV at hospital discharge 
Table 2. Comparisons of clinical outcomes between group R vs group S.

\begin{tabular}{|c|c|c|c|}
\hline \multirow{3}{*}{ Outcome } & Group R & Group S & \multirow[b]{2}{*}{$P$ value } \\
\hline & $\begin{array}{c}\text { Rapid EN } \\
\text { advancement }\end{array}$ & $\begin{array}{c}\text { Slow EN } \\
\text { advancement }\end{array}$ & \\
\hline & $\mathrm{n}=41$ & $\mathrm{n}=24$ & \\
\hline \multicolumn{4}{|l|}{ All-cause mortality } \\
\hline In EICU, n (\%) & $0(0)$ & $0(0)$ & 1.000 \\
\hline In hospital, n (\%) & $3(7)$ & $0(0)$ & 0.244 \\
\hline \multicolumn{4}{|l|}{ Length of stay } \\
\hline ICU-free days, days; median (IQR) & $19.0(13.5-22.0)$ & $20.5(15.3-23.0)$ & 0.309 \\
\hline Length of hospital stay, days; median (IQR) & $38.3(29.1-54.1)$ & $50.4(35.7-61.2)$ & 0.128 \\
\hline \multicolumn{4}{|l|}{ Mechanical ventilation } \\
\hline $\begin{array}{l}\text { Mechanical ventilation-free days, days; } \\
\text { median (IQR) }\end{array}$ & $18.0(0.0-22.0)$ & $21.0(16.3-24.8)$ & 0.046 \\
\hline $\begin{array}{l}\text { Requirement for mechanical ventilation at } \\
\text { hospital discharge, } \mathrm{n}(\%)\end{array}$ & $12(29)$ & $2(8)$ & 0.030 \\
\hline \multicolumn{4}{|l|}{ Tracheostomy, n (\%) } \\
\hline In EICU & $18(44)$ & $12(50)$ & 0.448 \\
\hline In hospital & $26(63)$ & $17(71)$ & 0.422 \\
\hline Antibiotic-free days, days; median (IQR) & $15.0(8.5-19.0)$ & $12.5(8.0-18.8)$ & 0.410 \\
\hline Highest CRP, mg/dl; median (IQR) & $16.0(9.6-22.9)$ & $16.2(8.3-21.6)$ & 0.703 \\
\hline \multicolumn{4}{|l|}{ Pneumonia } \\
\hline Clinical diagnosis of pneumonia, $\mathrm{n}(\%)$ & $16(39)$ & $9(38)$ & 0.559 \\
\hline Development of VAP, n (\%) & $1(2)$ & $0(0)$ & 0.631 \\
\hline \multicolumn{4}{|l|}{ Liver and kidney dysfunction } \\
\hline $\begin{array}{l}\text { Liver dysfunction (serum bilirubin }>1.2 \\
\mathrm{mg} / \mathrm{dl}), \mathrm{n}(\%)\end{array}$ & $9(22)$ & $6(25)$ & 0.503 \\
\hline $\begin{array}{l}\text { Renal dysfunction (serum creatinine }>1.2 \\
\mathrm{mg} / \mathrm{dl} \text { ) or requirement for RRT, } \mathrm{n}(\%)\end{array}$ & $16(39)$ & $4(17)$ & 0.052 \\
\hline \multicolumn{4}{|l|}{ Glycemic control } \\
\hline $\begin{array}{l}\text { Hypoglycemia }(<70 \mathrm{mg} / \mathrm{dl}) \text { free days, days; } \\
\text { median }(\mathrm{IQR})\end{array}$ & $28.0(26.5-28.0)$ & $28.0(27.0-28.0)$ & 0.539 \\
\hline \multicolumn{4}{|l|}{ Received insulin administration, $\mathrm{n}(\%)$} \\
\hline First week in EICU & $19(46)$ & $6(25)$ & 0.073 \\
\hline During 28 days after EICU admission & $22(54)$ & $8(33)$ & 0.092 \\
\hline \multicolumn{4}{|l|}{ Average insulin daily dose (units) } \\
\hline First week in EICU & $7.8(2.7-16.8)$ & $4.8(1.6-26.3)$ & 0.775 \\
\hline During 28 days after EICU admission & $2.5(0.6-11.0)$ & $1.2(0.4-20.6)$ & 0.386 \\
\hline \multicolumn{4}{|l|}{ Electrolytes } \\
\hline \multicolumn{4}{|l|}{ Hypophosphatemia (<2.7 mg/dl), n (\%) } \\
\hline First week in EICU & $18(44)$ & $8(33)$ & 0.193 \\
\hline During 28 days after EICU admission & $22(54)$ & $8(33)$ & 0.400 \\
\hline
\end{tabular}




\section{Continued}

Lowest serum $\mathrm{P}$ concentrations, $\mathrm{mg} / \mathrm{dl}$; median (IQR)

First week in EICU

$2.4(1.7-3.2)$

$2.4(1.8-3.0)$

During 28 days after EICU admission

Dose of $\mathrm{P}$ to treat hypophosphataemia, $\mathrm{mmol} /$ day; median (IQR)

First week in EICU

During 28 days after EICU admission

$0(0-0)$

$2.1(2.0-2.5)$

0.277

0.399

$(1.9-2.5)$
$0(0-0)$
$0(0-0)$

0.846

0.808

Data were provided as median and interquartile range for continuous variables and as number and percentage for categorical variables. Mann-Whitney $\mathrm{U}$ test was used for continuous data and Fisher's exact test for categorical data. Group R reached $25 \mathrm{kcal} / \mathrm{kg} /$ day within 3 days of EEN initiation; Group S reached $25 \mathrm{kcal} / \mathrm{kg} /$ day 4 or more days after EEN initiation. Energy intake included intake via enteral and parenteral routes; glucose infusions used for fluid support, drug dilution and correction of hypoglycemia; and lipids delivered with sedatives (e.g., propofol). Either oral or parenteral nutrition was not initiated within the first week of EICU admission. CRP $=$ C-reactive protein, $\mathrm{EEN}=$ early enteral nutrition, $\mathrm{EICU}=$ emergency intensive care unit, $\mathrm{EN}=$ enteral nutrition, $\mathrm{ICU}=$ intensive care unit, $\mathrm{IQR}=$ interquartile range, $\mathrm{P}=$ phosphorus, $\mathrm{RRT}=$ renal replacement therapy, $\mathrm{VAP}=$ ventilator associated pneumonia.

Table 3. Multiple logistic regression analysis of the requirement for mechanical ventilation at hospital discharge in 65 underweight EICU patients who received EEN.

\begin{tabular}{ccc}
\hline Independent variable & Adjusted OR (95\% CI) & P value \\
\hline Days to reach target energy intake from EEN initiation ${ }^{\dagger}$ & $0.467(0.245-0.889)$ & 0.020 \\
Initial SOFA & $1.324(0.990-1.769)$ & 0.058 \\
Admission category, medical/surgical & $0.458(0.064-3.287)$ & 0.438 \\
Source of admission & & \\
Emergency department & 1 (reference) & 0.686 \\
Emergency ward & $1.613(0.159-16.33)$ & 0.368 \\
Operating room & $0.243(0.011-5.282)$ & 0.762 \\
Other hospital & $1.656(0.064-43.11)$ & 0.657 \\
\hline
\end{tabular}

${ }^{\dagger}$ Energy target was set at $25 \mathrm{kcal} / \mathrm{kg} /$ day for all patients. Energy intake included intake via enteral and parenteral routes; glucose infusions used for fluid support, drug dilution and correction of hypoglycemia; and lipids delivered with sedatives (e.g., propofol). Either oral or parenteral nutrition was not initiated within the first week of EICU admission. $\mathrm{CI}=$ confidence interval, $\mathrm{EEN}=$ early enteral nutrition, $\mathrm{EICU}=$ emergency intensive care unit, SOFA = Sequential Organ Failure Assessment.

was significantly higher in those with rapid feeding advancement. Multivariable analyses with adjustment for confounders revealed that the number of days to reach target energy intake from EEN initiation was significantly and independently associated with the requirement for MV at hospital discharge, but not with the VFDs.

In our previous study, we only focused on mean daily energy intake during the first week of EICU admission [15]. In the present study, however, we focused on the rate of enteral feeding advancement after the initiation of EEN. We therefore conducted the present study in patients who initiated EN within the first $48 \mathrm{~h}$ of EICU admission and did not initiate oral or parenteral nutrition within the first week of EICU admission. 
Patients were categorized into two groups according to the days to reach the energy target, with Group $\mathrm{R}$ reaching this target within 3 days of EEN initiation and Group $\mathrm{S}$ reaching this target 4 or more days after EEN initiation. Although both groups initiated EN within the first $48 \mathrm{~h}$ of admission, Group R started EN significantly earlier than Group S. This earlier initiation and rapid rate of feeding advancement might account for the larger energy intake in Group R patients. Protein intake was significantly higher in Group $\mathrm{R}$ than in Group S. As all patients were given enteral formulas with a fixed energy-protein ratio, protein intake might have been dependent on energy intake. However, the present study focused on the rate of feeding advancement after initiation of EEN.

To our knowledge, this study is the first to evaluate the influence of the rate of feeding advancement after initiation of EEN on mortality and morbidity in underweight and critically ill and patients during emergency admission. Guidelines for critical care from the American Society for Parenteral and Enteral Nutrition (A.S.P.E.N.) recommend the advancement of feeding toward the target over the $48-72 \mathrm{~h}$ after the start of EEN [1], and the Canadian Clinical Practice Guidelines (CCPG) recommend starting at target feeding rate when initiating EN in critically ill patients [2]. Several studies support each of these recommendations [9]-[14]. Taylor et al. reported that enhanced EN (target feeding rate from Day 1) reduced infective complications compared to standard EN (gradual increase from $15 \mathrm{~mL} / \mathrm{h}$ ) [9]. Petros et al. compared the impact of normocaloric ( $100 \%$ of energy expenditure) vs. hypocaloric (50\% of energy expenditure) feeding in patients with a BMI of approximately $28 \mathrm{~kg} / \mathrm{m}^{2}$ in the first 7 days in an ICU [14], and found that the normocaloric group had a lower incidence of nosocomial infection than the hypocaloric group.

In contrast, several other studies do not support a rapid rate of feeding advancement for critically ill patients. Arabi et al. studied enterally-fed patients with a mean BMI of approximately $29 \mathrm{~kg} / \mathrm{m}^{2}$ and reported that underfeeding during the ICU stay (energy target: $60 \%-70 \%$ of calculated requirement) was associated with lower mortality than target feeding [6]. The INTACT trial evaluated the outcomes of intensive medical nutrition therapy (IMNT: provision of $>75 \%$ of estimated energy and protein requirements) compared to standard nutritional support in patients with a BMI of approximately $30 \mathrm{~kg} / \mathrm{m}^{2}$ [8]. Notably, this study was terminated early due to a significant increase in mortality in the intensive IMNT group ( $40 \%$ vs. $16 \%, \mathrm{P}=0.017)$. Other studies reported no significant effects of initial feeding rate on major outcomes [7] [24][28].

Most of the above studies were performed in patients aged from 50 to 70 years with a BMI of $>25 \mathrm{~kg} / \mathrm{m}^{2}$. In contrast, the patients in the present study had a BMI of $<20.0$ $\mathrm{kg} / \mathrm{m}^{2}$ and were older with median age of 73 years. These patients were admitted to the EICU to receive emergency medical or surgical treatment, while patients from general wards or were post-elective surgery were excluded. Low BMI is associated with higher complications and mortality in ICU as well as non-ICU settings [29]-[32]. Elevated risk of all-cause mortality for BMI $<21 \mathrm{~kg} / \mathrm{m}^{2}$ level has been reported in middle-aged and 
elderly people in Japan [33]. A negative balance of energy due to a slow rate of feeding advancement might diminish the adipose tissue mass of patients in order to meet energy expenditure. For most patients in previous studies, the impact of negative energy balance for short periods may have only been minor, as their fat reserves were normal or excessive. In contrast, fat and protein reserves in underweight patients with a BMI < $20 \mathrm{~kg} / \mathrm{m}^{2}$, such as the patients in our present study, are relatively limited. The impact of negative energy balance in these patients is therefore considered to be of greater importance than that in patients with normal or excessive BMI. On the other hand, in malnourished patients, particularly those with a BMI of $<18.5 \mathrm{~kg} / \mathrm{m}^{2}$, a rapid delivery of energy might induce refeeding syndrome [34]. Nevertheless, we observed no difference in the incidence of serum $\mathrm{P}$ concentration abnormalities between groups as symptomatic of refeeding syndrome (Table 2).

In our evaluation of the influence of rapid or slow feeding advancement after initiation of EEN on mortality and morbidity in critically ill medical and surgical patients with a BMI of $<20 \mathrm{~kg} / \mathrm{m}^{2}$, we observed that a slow advancement rate was associated with a lower requirement for MV at hospital discharge. However, the reliability of this result is statistically limited. Normally, multiple logistic regression analysis requires at least ten outcomes for one independent variable. Unfortunately, we were unable to adopt this method due to our small sample size. Several potential mechanisms might explain the association of rapid feeding advancement with an increased requirement for MV at hospital discharge. Increased feeding might have resulted in EN-related complications, for example aspiration pneumonia [35]. Although several patients in the present study did develop pneumonia (Table 2), the retrospective design of the study meant that we could not determine if this was caused by aspiration. Other variables we considered to be associated with prolonged MV were the primary reason for ICU admission, acute physiology score on Day 1, age, prior patient location and hospital length of stay, activity limits due to respiratory disease, serum albumin, respiratory rate, and the partial pressure arterial oxygen/fraction inspired oxygen ratio [36]. Unfortunately, the sample size of the present study was too small to allow multivariate analysis using all these variables as confounders. We therefore cannot deny the possibility that the requirement for MV was influenced by the underlying condition of the patient rather than the rate of feeding advancement.

Several limitations of the present study warrant mention. First and most importantly, sample size was small, and the study was conducted at a single institution. Further, study subjects were old Japanese with median age of 73 years. Our results are therefore limited and require confirmation in a larger sample size in patients with different generational and ethnic backgrounds. Second, the study was conducted under a retrospective design and groups were not randomized, which might have resulted in a degree of bias. Third, nutritional status was defined by BMI alone, which might be unreliable for nutritional assessment as actual body weight early in the clinical course might be influenced by non-nutrition factors such as fluid balance and inflammatory status. Further, we were unable to determine whether patients developed illness-related weight loss or were healthy despite their low body weight prior to EICU admission. Finally, an 
energy target was set at $25 \mathrm{kcal} / \mathrm{kg} /$ day for all patients, which was not tailored to the clinical status of each patient. In addition, the reason why physicians advanced EN rapider in Group $\mathrm{R}$ could not be identified. Thus, a conclusive answer to whether a slow rate of feeding advancement after the initiation of EEN improves outcomes in critically ill underweight patients requires large multicenter prospective studies with random patient assignment.

\section{Conclusion}

The results of this single-center, retrospective chart analysis demonstrate that a slow rate of feeding advancement after initiation of EEN in critically ill patients having a BMI of $<20.0 \mathrm{~kg} / \mathrm{m}^{2}$ might be associated with a reduced requirement for MV at hospital discharge. These results require confirmation in a large multicenter trial which enrolls underweight and critically ill patients.

\section{Acknowledgements}

The authors thank the EICU staff for their support, collection of data, and review of this manuscript.

\section{References}

[1] McClave, S.A., Taylor, B.E., Martindale, R.G., Warren, M.M., Johnson, D.R., Braunschweig, C., McCarthy, M.S., Davanos, E., Rice, T.W., Cresci, G.A., Gervasio, J.M., Sacks, G.S., Roberts, P.R. and Compher, C., Society of Critical Care Medicine, and American Society for Parenteral and Enteral Nutrition (2016) Guidelines for the Provision and Assessment of Nutrition Support Therapy in the Adult Critically Ill Patient: Society of Critical Care Medicine (SCCM) and American Society for Parenteral and Enteral Nutrition (A.S.P.E.N.). Journal of Parenteral and Enteral Nutrition, 40, 159-211. http://dx.doi.org/10.1177/0148607115621863

[2] Canadian Clinical Practice Guidelines Committee (2015) The 2015 Canadian Clinical Practice Guidelines. http://www.criticalcarenutrition.com/cpgs

[3] Kreymann, K.G., Berger, M.M., Deutz, N.E., Hiesmayr, M., Jolliet, P., Kazandjiev, G., Nitenberg, G., van den Berghe, G. and Wernerman, J., DGEM (German Society for Nutritional Medicine), Ebner, C., Hartl, W., Heymann, C. and Spies, C., ESPEN (European Society for Parenteral and Enteral Nutrition) (2006) ESPEN Guidelines on Enteral Nutrition: Intensive Care. Clinical Nutrition, 25, 210-223. http://dx.doi.org/10.1016/j.clnu.2006.01.021

[4] Ibrahim, E.H., Mehringer, L., Prentice, D., Sherman, G., Schaiff, R., Fraser, V. and Kollef, M.H. (2002) Early versus Late Enteral Feeding of Mechanically Ventilated Patients: Results of a Clinical Trial. Journal of Parenteral and Enteral Nutrition, 26, 174-181. http://dx.doi.org/10.1177/0148607102026003174

[5] Krishnan, J.A., Parce, P.B., Martinez, A., Diette, G.B. and Brower, R.G. (2003) Caloric Intake in Medical ICU Patients: Consistency of Care with Guidelines and Relationship to Clinical Outcomes. Chest, 124, 297-305. http://dx.doi.org/10.1378/chest.124.1.297

[6] Arabi, Y.M., Tamim, H.M., Dhar, G.S., Al-Dawood, A., Al-Sultan, M., Sakkijha, M.H., Kahoul, S.H. and Brits, R. (2011) Permissive Underfeeding and Intensive Insulin Therapy in Critically Ill Patients: A Randomized Controlled Trial. American Journal of Clinical Nutrition, 93, 569-577. http://dx.doi.org/10.3945/ajcn.110.005074 
[7] National Heart, Lung, and Blood Institute Acute Respiratory Distress Syndrome (ARDS) Clinical Trials Network, Rice, T.W., Wheeler, A.P., Thompson, B.T., Steingrub, J., Hite, R.D., Moss, M., Morris, A., Dong, N. and Rock, P. (2012) Initial Trophic vs Full Enteral Feeding in Patients with Acute Lung Injury: The EDEN Randomized Trial. JAMA, 307, 795-803. http://dx.doi.org/10.1001/jama.2012.137

[8] Braunschweig, C.A., Sheean, P.M., Peterson, S.J., Gomez Perez, S., Freels, S., Lateef, O., Gurka, D. and Fantuzzi, G. (2015) Intensive Nutrition in Acute Lung Injury: A Clinical Trial (INTACT). Journal of Parenteral and Enteral Nutrition, 39, 13-20. http://dx.doi.org/10.1177/0148607114528541

[9] Taylor, S.J., Fettes, S.B., Jewkes, C. and Nelson, R.J. (1999) Prospective, Randomized, Controlled Trial to Determine the Effect of Early Enhanced Enteral Nutrition on Clinical Outcome in Mechanically Ventilated Patients Suffering Head Injury. Critical Care Medicine, 27, 2525-2531. http://dx.doi.org/10.1097/00003246-199911000-00033

[10] Rubinson, L., Diette, G.B., Song, X., Brower, R.G. and Krishnan, J.A. (2004) Low Caloric Intake Is Associated with Nosocomial Bloodstream Infections in Patients in the Medical Intensive Care Unit. Critical Care Medicine, 32, 350-357. http://dx.doi.org/10.1097/01.CCM.0000089641.06306.68

[11] Villet, S., Chiolero, R.L., Bollmann, M.D., Revelly, J.P., Cayeux, R.N.M.C., Delarue, J. and Berger, M.M. (2005) Negative Impact of Hypocaloric Feeding and Energy Balance on Clinical Outcome in ICU Patients. Clinical Nutrition, 24, 502-509. http://dx.doi.org/10.1016/j.clnu.2005.03.006

[12] Dvir, D., Cohen, J. and Singer, P. (2006) Computerized Energy Balance and Complications in Critically Ill Patients: An Observational Study. Clinical Nutrition, 25, 37-44. http://dx.doi.org/10.1016/j.clnu.2005.10.010

[13] Alberda, C., Gramlich, L., Jones, N., Jeejeebhoy, K., Day, A.G., Dhaliwal, R. and Heyland, D.K. (2009) The Relationship between Nutritional Intake and Clinical Outcomes in Critically Ill Patients: Results of an International Multicenter Observational Study. Intensive Care Medicine, 35, 1728-1737. http://dx.doi.org/10.1007/s00134-009-1567-4

[14] Petros, S., Horbach, M., Seidel, F. and Weidhase, L. (2016) Hypocaloric vs Normocaloric Nutrition in Critically Ill Patients: A Prospective Randomized Pilot Trial. Journal of Parenteral and Enteral Nutrition, 40, 242-249. http://dx.doi.org/10.1177/0148607114528980

[15] Ichimaru, S., Fujiwara, H., Amagai, T. and Atsumi, T. (2014) Low Energy Intake during the First Week in an Emergency Intensive Care Unit Is Associated with Reduced Duration of Mechanical Ventilation in Critically Ill, Underweight Patients: A Single-Center Retrospective Chart Review. Nutrition in Clinical Practice, 29, 368-379. http://dx.doi.org/10.1177/0884533614529162

[16] Heyland, D.K., Cahill, N. and Day, A.G. (2011) Optimal Amount of Calories for Critically Ill Patients: Depends on How You Slice The Cake! Critical Care Medicine, 39, 2619-2626. http://dx.doi.org/10.1097/CCM.0b013e318226641d

[17] Knaus, W.A., Draper, E.A., Wagner, D.P. and Zimmerman, J.E. (1985) APACHE II: A Severity of Disease Classification System. Critical Care Medicine, 13, 818-829. http://dx.doi.org/10.1097/00003246-198510000-00009

[18] Ferreira, F.L., Bota, D.P., Bross, A., Mélot, C. and Vincent, J.L. (2001) Serial Evaluation of the SOFA Score to Predict Outcome in Critically Ill Patients. JAMA, 286, 1754-1758. http://dx.doi.org/10.1001/jama.286.14.1754

[19] Charlson, M., Szatrowski, T.P., Peterson, J. and, Gold J. (1994) Validation of a Combined Comorbidity Index. Journal of Clinical Epidemiology, 47, 1245-1251. http://dx.doi.org/10.1016/0895-4356(94)90129-5 
[20] World Health Organization (2011) Haemoglobin Concentrations for the Diagnosis of Anaemia and Assessment of Severity.

http://www.who.int/vmnis/indicators/haemoglobin.pdf

[21] National Healthcare Safety Network (NHSN) (2015) Ventilator-Associated Event (VAE). http://www.cdc.gov/nhsn/PDFs/pscManual/10-VAE_FINAL.pdf

[22] McMahon, M.M., Nystrom, E., Braunschweig, C., Miles, J. and Compher, C., American Society for Parenteral and Enteral Nutrition (ASPEN) Board of Directors, and American Society for Parenteral and Enteral Nutrition (2013) ASPEN Clinical Guidelines: Nutrition Support of Adult Patients with Hyperglycemia. Journal of Parenteral and Enteral Nutrition, 37, 23-36. http://dx.doi.org/10.1177/0148607112452001

[23] Rhoda, K.M., Porter, M.J. and Quintini, C. (2011) Fluid and Electrolyte Management: Putting a Plan in Motion. Journal of Parenteral and Enteral Nutrition, 35, 675-685. http://dx.doi.org/10.1177/0148607111421913

[24] Rice, T.W., Mogan, S., Hays, M.A., Bernard, G.R., Jensen, G.L. and Wheeler, A.P. (2011) Randomized Trial of Initial Trophic versus Full-Energy Enteral Nutrition in Mechanically Ventilated Patients with Acute Respiratory Failure. Critical Care Medicine, 5, 967-974. http://dx.doi.org/10.1097/CCM.0b013e31820a905a

[25] Desachy, A., Clavel, M., Vuagnat, A., Normand, S., Gissot, V. and François, B. (2008) Initial Efficacy and Tolerability of Early Enteral Nutrition with Immediate or Gradual Introduction in Intubated Patients. Intensive Care Medicine, 34, 1054-1059. http://dx.doi.org/10.1007/s00134-007-0983-6

[26] Doig, G.S., Simpson, F., Finfer, S., Delaney, A., Davies, A.R., Mitchell, I. and Dobb, G. and Nutrition Guidelines Investigators of the ANZICS Clinical Trials Group (2008) Effect of Evidence-Based Feeding Guidelines on Mortality of Critically Ill Adults: A Cluster Randomized Controlled Trial. JAMA, 300, 2731-2741. http://dx.doi.org/10.1001/jama.2008.826

[27] Charles, E.J., Petroze, R.T., Metzger, R., Hranjec, T., Rosenberger, L.H., Riccio, L.M., McLeod, M.D., Guidry, C.A., Stukenborg, G.J., Swenson, B.R., Willcutts, K.F., O’Donnell, K.B. and Sawyer, R.G. (2014) Hypocaloric Compared with Eucaloric Nutritional Support and Its Effect on Infection Rates in a Surgical Intensive Care Unit: A Randomized Controlled Trial. The American Journal of Clinical Nutrition, 100, 1337-1343. http://dx.doi.org/10.3945/ajcn.114.088609

[28] Arabi, Y.M., Aldawood, A.S., Haddad, S.H., Al-Dorzi, H.M., Tamim, H.M., Jones, G., Mehta, S., McIntyre, L., Solaiman, O., Sakkijha, M.H., Sadat, M. and Afesh, L. and PermiT Trial Group (2015) Permissive Underfeeding or Standard Enteral Feeding in Critically Ill Adults. New England Journal of Medicine, 372, 2398-2408. http://dx.doi.org/10.1056/NEJMoa1502826

[29] Engeland, A., Bjørge, T., Selmer, R.M. and Tverdal, A. (2003) Height and Body Mass Index in Relation to Total Mortality. Epidemiology, 14, 293-299. http://dx.doi.org/10.1097/01.EDE.0000047889.30616.73

[30] Song, Y.M. and Sung, J. (2001) Body Mass Index and Mortality: A Twelve-Year Prospective Study in Korea. Epidemiology, 12, 173-179. http://dx.doi.org/10.1097/00001648-200103000-00008

[31] Tremblay, A. and Bandi, V. (2003) Impact of Body Mass Index on Outcomes Following Critical Care. Chest, 123, 1202-1207. http://dx.doi.org/10.1378/chest.123.4.1202

[32] Garrouste-Orgeas, M., Troché, G., Azoulay, E., Caubel, A., de Lassence, A., Cheval, C., Montesino, L., Thuong, M., Vincent, F., Cohen, Y. and Timsit, J.F. (2004) Body Mass Index: An Additional Prognostic Factor in ICU Patients. Intensive Care Medicine, 30, 437-443. http://dx.doi.org/10.1007/s00134-003-2095-2 
[33] Sasazuki, S., Inoue, M., Tsuji, I., Sugawara, Y., Tamakoshi, A., Matsuo, K., Wakai, K., Nagata, C., Tanaka, K., Mizoue, T. and Tsugane, S. and Research Group for the Development and Evaluation of Cancer Prevention Strategies in Japan (2011) Body Mass Index and Mortality from All Causes and Major Causes in Japanese: Results of a Pooled Analysis of 7 Large-Scale Cohort Studies. Journal of Epidemiology, 21, 417-430.

http://dx.doi.org/10.2188/jea.JE20100180

[34] National Collaborating Centre for Acute Care (2006) What to Give in Hospital and the Community. Nutrition Support for Adults: Oral Nutrition Support, Enteral Tube Feeding and Parenteral Nutrition. http://www.ncbi.nlm.nih.gov/books/NBK49256/

[35] Mentec, H., Dupont, H., Bocchetti, M., Cani, P., Ponche, F. and Bleichner, G. (2001) Upper Digestive Intolerance during Enteral Nutrition in Critically Ill Patients: Frequency, Risk Factors, and Complications. Critical Care Medicine, 29, 1955-1961. http://dx.doi.org/10.1097/00003246-200110000-00018

[36] Seneff, M.G., Zimmerman, J.E., Knaus, W.A., Wagner, D.P. and Draper, E.A. (1996) Predicting the Duration of Mechanical Ventilation. The Importance of Disease and Patient Characteristics. Chest, 110, 469-479. http://dx.doi.org/10.1378/chest.110.2.469

Submit or recommend next manuscript to SCIRP and we will provide best service for you:

Accepting pre-submission inquiries through Email, Facebook, LinkedIn, Twitter, etc. A wide selection of journals (inclusive of 9 subjects, more than 200 journals)

Providing 24-hour high-quality service

User-friendly online submission system

Fair and swift peer-review system

Efficient typesetting and proofreading procedure

Display of the result of downloads and visits, as well as the number of cited articles Maximum dissemination of your research work

Submit your manuscript at: http://papersubmission.scirp.org/ 